The Pennsylvania State University

DE-FG07-98ID13637

(DOE-NEER Project)

\title{
Report for Phase 3 and Final Project Report \\ Study of Second Phase Particles and Fe content in Zr Alloys \\ Using the Advanced Photon Source at Argonne
}

P.I.: Arthur T. Motta, The Pennsylvania State University

Report Period: Overall Project Period (August 16, 1998 to August 15, 2001) with emphasis on Phase III (August 16, 2000 to August 15, 2001) 


\section{Table of Contents}

Executive Summary

Deliverables $\quad 3$

1. Introduction 5

2. Bulk Diffraction Studies 6

2.1. Identification of precipitate crystal structures 8

2.2. Precipitate Size from Line Broadening 9

2.3. Quantification of absolute precipitate volume fraction 10

3. Microbeam Fluorescence of Alloying Elements in the matrix of Zr alloys 10

3.1 X-ray Fluorescence Measurements. 11

3.2. Monte Carlo Simulation of Fluorescence Spectra 12

4. Neutron-Irradiated samples $\quad 13$

5. Tables 15

6. Figure Captions 19

$\begin{array}{ll}7 . \text { Figures } & 20\end{array}$

Appendix: Publications and Student Theses generated in the project 29

8. References 30

$\begin{array}{lll}\text { A. T. Motta } & \text { Final Report DE-FG07-98_ID13637 }\end{array}$ 


\section{Executive Summary}

We present here the progress report for Phase III and the Final Report for the project above. The overall aim of this project was to investigate the state of alloying elements and second phase particles in $\mathrm{Zr}$ alloys using synchrotron radiation from the Advanced Photon Source (APS) at Argonne National Laboratory. Several zirconium alloys have been investigated with the aim of determining both the volume fraction and crystal structure of minute amounts of second phase precipitate particles using $\mathrm{x}$-ray diffraction and the alloying content in the zirconium matrix using $\mu$ beam $x$-ray fluorescence.

The objectives for phase 3 in last year's report, are listed below:

1. To obtain reliable values for the Fe concentration in the hcp- $\mathrm{Zr}$ matrix of nonirradiated $\mathrm{Zr}$ alloys using the microbeam facilities in the 2IDD and 2IDE beam lines in the SRI-CAT at APS; the alloys to be studied include ultra purity $\mathrm{Zr}$, Zircaloy-2, Zircaloy 4 and ZIRLO. We will use the high-resolution beam line (2ID-D) at SRICAT at APS and Monte Carlo simulation, as detailed in the phase 2 report to obtain accurate values of the Fe matrix content.

2. To quantify using carefully controlled x-ray diffraction experiments and standards, the precipitate volume fraction in the zirconium alloy matrix as a function of heat treatment. To achieve this we will perform detailed examinations in the 2BM beamline of the SRI-CAT at APS, and analyze the results using Rietveld analysis.

These objectives, as well as the overall program objectives have been accomplished and surpassed. For objective number 1, not only these alloys but others were studied, using the microfluorescence beams at the 2-IDE and 2ID-D beamline at Argonne. The second beamline has a higher resolution ( 0.25 micron compared to 0.5 micron at 2ID-E) and allowed us to obtain reliable values of the Fe matrix content. We have also performed Monte Carlo simulations of the fluorescence process and can therefore reproduce and predict the fluorescence spectra we measure. For objective number 2, we have studied both Zircaloy-2 and Zircaloy-4 and ZIRLO, in various states of heat treatment, from asquenched to highly annealed. We have not only verified that the precipitates can be detected and identified but also verified that one can observe the kinetics of precipitate nucleation and growth using synchrotron radiation. We have performed quantitative diffraction analysis of the data to quantify the precipitates size and volume fraction.

\section{Deliverables}

The main scientific results of the research project are as follows:

- We identified the second phase precipitates in bulk Zircaloy-4, Zircaloy-2 and ZIRLO, finding good agreement with literature values where those were known. We followed the precipitation kinetics in various zirconium alloys, as a function 
of annealing parameter. We found that the greater part of the precipitation occurs between $10^{-19}$ and $10^{-18} \mathrm{~h}$.

- We determined the precipitate size from the diffraction line broadening. The average $\mathrm{Zr}(\mathrm{Cr}, \mathrm{Fe})_{2}$ precipitate size in Zircaloy-4, as measured from the line broadening, increases from $10 \mathrm{~nm}$ at $10^{-20} \mathrm{~h}$ to $120 \mathrm{~nm}$ at $10^{-16} \mathrm{~h}$.

- Our results show that, using synchrotron radiation, it is possible to detect and quantify the very small volume fractions of second phase particles in the bulk zirconium alloy, which opens up the possibility of studying precipitate evolution in bulk irradiated material and of creating more detailed relationship between alloy microstructure and behavior.

- We performed measurements of the alloying element concentration in the matrix of $\mathrm{Zr}$ alloys, finding good agreement for the homogeneous alloys (quenched alloys, nominally pure and ultra pure $\mathrm{Zr}$ ).

- The analysis of the spectra obtained from the matrix of Zircaloy-4 at $10^{-16} \mathrm{~h}$ indicate Fe matrix concentrations on the order of $300 \mathrm{ppm}$ and $\mathrm{Cr}$ concentrations on the order of $270 \mathrm{ppm}$. These concentrations, much above the solubility limit for $\mathrm{Fe}$ in pure $\mathrm{Zr}$ indicate that $\mathrm{Fe}$ and $\mathrm{Cr}$ are either in a metastable solution or are stabilized .in solution by the other alloying elements.

This work shows that synchrotron radiation is an extremely useful tool for obtaining detailed microstructural information of metallic alloys, in the bulk, and spatially resolved on a sub-micron scale. One of the significant consequences of this work is that it reveals a bulk characterization technique that can reveal detailed information about the microstructure of the alloy, which can be used for alloy optimization.

The principal product of the project is this Final Report, which details the work that led to the scientific conclusions above. The research project also resulted in several refereed publications in scientific journals and presentations in Conferences; these are listed in Appendix A. In addition, two M.S. theses in Nuclear Engineering were completed in the context of this work and one more is on the way. These are also listed in the appendix A. Thus, three graduate students have been educated as a direct result of this research.

Finally, this research created a collaboration between The Pennsylvania State University and Argonne National Laboratory, which has borne considerable fruit as well as creation of expertise in both university and National Laboratory that is being used in other research projects, including a NERI research grant. 


\section{Introduction}

During the last funding period (Phase III), we achieved several milestones, which allowed us to achieve the main objectives specified in both areas of the project. We conducted several runs in the diffraction line at APS to obtain data that will allow us to evaluate the volume fraction of second-phase precipitates in zirconium alloys as a function of heat treatment. To our knowledge the ensemble of these observations represent the first time that such minute amounts of second phase particles were detected using a bulk diffraction technique. These observations are the subject of one conference publication and a recent journal publication 1,2 and one M.S. Thesis ${ }^{3}$. We have also performed quantitative analysis of the diffraction spectra using the Rietveld method, as well as performing peak area analysis using the Peak Fit program. As a result of this analysis we were able to evaluate the amount of second phase particles in zirconium alloys, as a function of processing route. The availability of this bulk characterization technique that can study minute amounts of second phase particles can open the door to detailed understanding of the evolution of microstructure as function of processing route and irradiation conditions. 4 .

We also conducted further examinations of the matrix of several alloys and standards in the micro-fluorescence line at APS, with the aim of detecting the amount of alloying elements in the alpha-matrix of zirconium alloys. In this funding period we used the higher resolution line at 2ID-D which has a spatial resolution of 0.25 micron. This allows us to sample the $\mathrm{Fe}$ concentration from a region that contains only the $\mathrm{Zr}$ matrix. We have analyzed various alloys and fabricated standards with a homogeneous distribution of alloying elements, with results that fit well with existing knowledge. We have also conducted microbeam fluorescence examinations in alloys with a heterogeneous distribution of alloying elements (second phase intermetallic precipitates in a zirconium matrix) and found results that are also in agreement with our analysis. To analyze these results we have performed Monte Carlo simulations of the fluorescence process 5,6 . These analyses were the subject of one conference presentation 7 , and two journal publications 4,8 and resulted in a M.S. thesis 9 .

The research project was very successful, producing new information and revealing the potential of a new technique to analyze the microstructure of zirconium alloys.

Samples Examined: Table 1 gives the concentrations (and the elemental detection limits) of the different alloys examined in this work, as measured by hot vacuum extraction. Zircaloy-4 and Zircaloy-2 samples were obtained from the General Electric Corporation as plate material. Samples suitable for x-ray diffraction were cut from the plate with a low-speed diamond saw and mechanically polished on a mechanical milling machine using $15 \mu \mathrm{m} \mathrm{SiC} \mathrm{paper.} \mathrm{ZIRLO} \mathrm{was} \mathrm{obtained} \mathrm{from} \mathrm{Westinghouse} \mathrm{Electric} \mathrm{Corporation} \mathrm{in}$ the form of tubing. Flat sections measuring about $5 \times 10 \times 0.5 \mathrm{~mm}$ were prepared for $\mathrm{x}$ ray diffraction by cutting, mechanically grinding and polishing. 
These samples were annealed in a quartz tube filled with ultra-high purity Ar for ten minutes at $1170 \mathrm{~K}$ to completely dissolve the precipitates and put the alloying elements back into solution in the matrix. After the heat treatment, the samples were quenched by breaking the quartz tube over a bucket of water. A small amount of discoloration in these samples resulting from the heat treatment was removed by further mechanical polishing. After quenching, the samples were re-sealed into quartz tubes and annealed to various values of the Cumulative Annealing Parameter (CAP) ${ }^{10}$, defined as:

$$
C A P=\sum_{i} t_{i} \exp \left(-Q / R T_{i}\right)
$$

where $t_{i}$ is the time (hours) spent at temperature $T_{i}(\mathrm{~K})$ and $\mathrm{Q} / \mathrm{R}=40,000 \mathrm{~K}$. Table 2 shows the range of annealing parameters for the samples studied.

The samples used in x-ray fluorescence experiments were standard TEM thin foils (about $100 \mathrm{~nm}$ thick in their thinnest region) prepared from strips of the alloys that were brought to different cumulative annealing parameters with the heat-treatment procedure described above. These foils were prepared by mechanically grinding the strips to a thickness of approximately $100 \mu \mathrm{m}$, punching out $3 \mathrm{~mm}$ diameter disks, then electropolishing in a solution of $670 \mathrm{ml}$ methanol, $100 \mathrm{ml}$ of butoxyethanol and $130 \mathrm{ml} \mathrm{HCl}$, at a temperature of $-60 \mathrm{C}$ and an electropolishing current of $20 \mathrm{~mA}$. These samples were examined by transmission electron microscopy in a Philips CM-30 transmission electron microscope at Argonne National Laboratory and at a Hitachi FE 2000 at Penn State.

The microstructures of the quenched and annealed materials were examined by TEM. Bright field micrographs of quenched Zircaloy-4, annealed Zircaloy-4 and annealed ZIRLO are shown in Figure 2. The precipitate particles in Zircaloy-4 were indexed as the $\mathrm{C} 14$ hcp Laves Phase ( $\mathrm{MgZn}_{2}$-type) commonly found in this alloy. The ZIRLO particles were indexed either bcc $\beta-\mathrm{Nb}$ or as $\mathrm{Zr}-\mathrm{Nb}-\mathrm{Fe}$ particles with an hep structure, that has been recently been indexed as having the same structure as the $\mathrm{Zr}(\mathrm{Cr}, \mathrm{Fe})_{2} \mathrm{C} 14$ Laves phase, in agreement with previous studies 11,12 . The quenched alloy showed no indication of second phase precipitation. The lath boundaries of the quenched alloy were examined with EDS and no alloying element enrichment detected.

2. Bulk diffraction studies (students: Ken Erwin and Olivier Delaire, Collaborators: Y.Chu, D.Mancini (SRI-CAT, ANL), R.Birtcher (MSD-ANL))

Bulk X-ray diffraction was performed at the 2-BM beamline at the SRI-CAT at the Advanced Photon Source at Argonne. Figure 1 (a) shows the beamline setup and Figure 1 (b) shows the acquisition geometry. The storage ring emits synchrotron radiation of continuous wavelength called white the $\mathrm{x}$-ray beam. The apertured white beam is reflected off a $\mathrm{Cr}$ mirror, which serves as a low pass filter with a high-energy cut-off of $20 \mathrm{keV}$. A double crystal $\mathrm{Si}(111)$ monochromator selects a monochromatic X-ray beam with a bandwidth of $\delta \mathrm{E} / \mathrm{E} \sim 10^{-4}$. The size of the incident beam onto the sample is defined by the sets of slits. The intensity of the incident beam is measured by an ion chamber and 
is used to normalize the diffracted intensity. The sample is mounted on a standard fourcircle diffractometer, and the diffracted beam is measured by a NaI scintillation detector. The slits before the detector are used to reduce the unwanted background produced by the incident beam. The energy used was $13 \mathrm{keV}(\lambda=0.95348 \mathrm{~nm})$. We examined ZIRLO, Zircaloy-2 Zircaloy- 4 in the as-quenched state and after successive annealing schedules as described in table in Table 2 . The chi and phi angles were kept at 90 and 0 degrees, respectively.

We have performed three experimental runs at APS, on 8/01,3/01 and 11/00 to examine zirconium alloys and especially prepared standards in the 2BM (bending magnet) line at the SRI-CAT at Argonne in the current funding period. A significant fraction of our travel budget was spent on those trips. The detailed results we obtained are summarized in the following sections.

These examinations, aided by complementary experiments in the TEM and by computer analysis of the diffraction patterns using GSAS, have demonstrated that this technique can provide a measure of the precipitate volume fraction in these alloys, and that precipitation of second phases can be detected at very small values of the annealing parameter (CAP) and followed quantitatively as a function of heat treatment.

Figure 3 shows $x$-ray diffraction patterns obtained with synchrotron radiation (intensity vs. two-theta angle) for Zircaloy-4, Zircaloy- 2 and ZIRLO in the fully recrystallized state $\left(10^{-16} \mathrm{~h}\right.$ for Zircaloys and $10^{-18} \mathrm{~h}$ for ZIRLO). We can index the peaks in the Zircaloy-4 spectrum as corresponding either to the $\alpha-\mathrm{Zr}$ hcp phase or the $\mathrm{C} 14 \mathrm{Zr}(\mathrm{Cr}, \mathrm{Fe})_{2}$ hcp Laves phase $\left(\mathrm{MgZn}_{2}\right.$-type). The lattice parameters determined from the fit of the data correspond very well to the powder diffraction files for $\mathrm{C} 14 \mathrm{hcp} \mathrm{Zr}(\mathrm{Cr}, \mathrm{Fe})_{2}$ (JCPDF File \# 42-1289) 1 . There are faint indications of $\mathrm{Zr}_{2}(\mathrm{Ni}, \mathrm{Fe})$ peaks in Zircaloy-4, which could be related to the fact that low densities of the Ni-based precipitates are found in Zircaloy4 , because the small impurity level amount of $\mathrm{Ni}$ ends up in these types of precipitates. In the Zircaloy-2 diffraction pattern, the same peaks are present but there are additional peaks which can be indexed as the body-centered tetragonal $\mathrm{C} 16 \mathrm{Zr}_{2}(\mathrm{Ni}, \mathrm{Fe})$ phase (JCPDF File \# 38-1170). For ZIRLO, in addition to $\alpha-Z r, \beta-N b$ peaks with the bcc crystal structure are indexed in the Figure (JCPDF File \# 35-0789). The remaining peaks can be indexed as the $\mathrm{C} 14$ phase, and can likely be identified with the $\mathrm{Zr}-\mathrm{Nb}-\mathrm{Fe}$ phase seen by Sabol et al. 12 and Erwin et al. ${ }^{1}$. The results in Figure 3 demonstrate that the small volume fractions of second phase particles $(<0.2-0.4 \%)$ can be detected and identified using synchrotron radiation. We note that it is possible to obtain some indication of these second phase peaks by conventional $x$-ray diffraction 1 . However, the counting times are much higher and the peaks much less well defined, so that much less information is available. We should also note that a few peaks in Figure 3 are not indexed but have been empirically associated with a phase because they appear whenever the particular phase is present. The obvious candidates for additional phases present in Zircaloy-4, such $\mathrm{Zr}_{3} \mathrm{Fe}$ or cubic $\mathrm{Zr}(\mathrm{Cr}, \mathrm{Fe})_{2}$ were tested, but found not to correspond to these peaks. The range of possible particles in Zircaloy-4 includes a variety of silicides and phosphides, and it is possible that the unindexed peaks originate from some of these phases.
A. T. Motta
Final Report DE-FG07-98_ID13637 
We used synchrotron radiation to examine a series of Zircaloy- 2 and Zircaloy- 4 samples in the quenched state and after annealing up to $C A P=10^{-16} \mathrm{~h}$. The results of this examination are shown in Figure 4. In the as-quenched material, both for Zircaloy-2 and Zircaloy-4, only the $\alpha-Z r$ peaks are observed. The $\mathrm{Zr}$ peaks are fairly broad, in agreement with the small grain size of the quenched microstructure. As the annealing parameter increases, the $\alpha-Z r$ peaks become sharper and new peaks appear which correspond to the second phase particles. For Zircaloy-4 these peaks correspond to the $\mathrm{C} 14 \mathrm{Zr}(\mathrm{Cr}, \mathrm{Fe})_{2}$ phase. The second phase particle peaks are also initially broad $\left(\mathrm{CAP}=10^{-20} \mathrm{~h}\right)$ and of low intensity, indicating a small amount of second phase precipitated at that stage, in the form of very fine particles, which are also possibly strained. As the CAP increases, the peaks sharpen and grow, indicating further precipitation out of solid solution and an increase in precipitate size. In Zircaloy- 2 we see, in addition to the $\mathrm{C} 14$ phase peaks, the peaks corresponding to the $\mathrm{Zr}_{2}(\mathrm{Ni}, \mathrm{Fe})$ phase, (indicated in figure 3 ) which also grow and sharpen.

2.1 Identification of precipitate crystal structures

We have performed an initial analysis of our diffraction data by locating the peaks and manually fitting the expected phases for an optimized value of the lattice parameter. The measured values of the $\alpha-Z r$ matrix lattice parameter are $\mathrm{a}=0.3233 \mathrm{~nm}$ and $\mathrm{c}=0.5159 \mathrm{~nm}$, which are similar to the literature values of 0.3232 and $0.5147 \mathrm{~nm}$ (JCPDF File \# 5-065). We also performed this analysis for the second phase particles. The chemistry of the second-phase particles $(\mathrm{Fe} / \mathrm{Cr}$ or $\mathrm{Fe} / \mathrm{Ni}$ ratios) affects their lattice parameter, as does the presence of size misfit stresses from precipitation of incoherent particles. In the latter case the misfit strains could be as high as $\sigma_{y}^{M} / E^{p p t}$ for a precipitate that is harder than the matrix. Therefore, the lattice parameter of the particles in the alloy does not necessarily correspond to that in the JCPDF files and we fit the results to find the lattice parameter for the phases of interest.

The analysis yielded the values for the lattice parameters of the precipitates in the alloys shown in Table 4. These values are in good agreement with published values of the lattice parameters for these crystal structures from TEM studies ${ }^{13}$. For the $\mathrm{Zr}_{2}(\mathrm{Ni}, \mathrm{Fe})$ phase, the $\mathrm{Ni} / \mathrm{Fe}$ ratio determines the lattice parameter, as determined by Havinga and coworkers ${ }^{14}$. The best fit to our data implies a $\mathrm{Ni} / \mathrm{Fe}$ ratio of about 9 in the precipitates.

The analysis of the precipitate volume fraction from the $\mathrm{x}$-ray data is complicated by the fact that there are different types of precipitates, and their relative proportions depend on non-equilibrium processes of alloying element partitioning between the second-phase and the matrix. We performed some additional analysis, on the simplest case we had, that of Zircaloy-4, which has only one type of precipitate. We analyzed the $x$-ray pattern from a series of Zircaloy- 4 measurements using the Rietveld method as implemented in the GSAS program 15,16. The Rietveld Method creates a fit to the X-ray data by simultaneously varying several parameters, including crystal structure parameters, scattering factors, and equipment characteristics. The method fits the spectrum as a whole 
and, as such, it yields simultaneously all the pattern parameters, including as lattice parameters, volume fractions, texture, etc. We calculated the precipitate volume fraction at each CAP using this method.

For the Zircaloy-4 annealing experiment shown in Figure 4, we calculated the precipitate volume fraction from the GSAS fit of the data. Figure 7 shows the precipitate volume fraction as a function of CAP, normalized to the measured precipitate volume fraction at

$\mathrm{CAP}=10^{-16} \mathrm{~h}$ calculated from the measurement. The normalization process factors out the lack of knowledge in the absolute value of the volume fraction introduced by unknown values of the GSAS parameters. Assuming total precipitation of the alloying elements and assuming the composition reported in table 2 , we calculate a volume fraction of $0.45 \%$ at $10^{-16} \mathrm{~h}$ (not considering any corrections to precipitates volume from misfit strains and/or defects such as stacking faults which may be present in the precipitates). The actual value of the volume fraction will be smaller than this, as some of the alloying elements will be dissolved in the matrix. The precipitate volume fraction increases with increasing annealing parameter, showing an S-shape. The data shows that most of the precipitation occurs between $10^{-19} \mathrm{~h}$ and $10^{-18} \mathrm{~h}$.

\subsection{Precipitate Size from Line Broadening}

We can also use the data to estimate the size of the precipitates from the line-broadening of the precipitate peaks associated with particle size. The particle size $d$ is given by the Scherrer equation 17 :

$d=\frac{0.9 \lambda}{B_{\theta} \cos \theta}$

where $B_{\theta}=\left(B^{2}-B_{i}{ }^{2}\right)^{1 / 2}$ is the particle size broadening for peak $\theta, B$ is the measured peak broadening (full-width half maximum, FWHM), $B_{i}$ is the instrumental broadening measured using a standard, $\theta$ is the diffraction angle and $\lambda$ is the wavelength of the synchrotron radiation. Using a pattern measured from $\mathrm{LaB}_{6}$ standard obtained from NIST we determined the instrumental broadening in this case to be 0.039 degrees twotheta. This technique for measuring particle size is useful in the range $0-100 \mathrm{~nm}$, which coincidentally is the range of greater interest for the present experiments, as the precipitate size when fully annealed is on the order of $100-200 \mathrm{~nm} 10$.

The $\mathrm{Zr}$ peaks show little broadening for CAP above $10^{-20} \mathrm{~h}$, but the particle peaks clearly sharpen as the CAP increases. We calculated the particle sizes for the second phase peaks shown in Figures 3 and 4, using the 200 and 112 peaks located at between 25 and 26 degrees two-theta. The reason for this choice is that these peaks are reasonably isolated and because they are present in samples with CAP as low as $10^{-20} \mathrm{~h}$. We determined the FWHM of the peaks by fitting the peak profiles using a Pearson VII-type curve shape (after subtracting background) using the program PeakFit 4.0, to determine the FWHM. These results show a degree of variability of $10 \%$ from one fit to the other. The particle size results calculated using equation 2 are plotted in Figure 8 against the log of the CAP. 
It is clear that the particle size increases continuously until $10^{-17} \mathrm{~h}$, at which point the particle size saturates. The range of particle sizes calculated here corresponds reasonably well with the particle size seen in TEM examinations of these samples. Gros and Wadier 10 show the average precipitate size in Zircaloy- 4 gradually increases to about 150-200 $\mathrm{nm}$ at $10^{-16} \mathrm{~h}$, and show a value of $100 \mathrm{~nm}$ at $10^{-18} \mathrm{~h}$. In the present calculation, the corresponding values are $120 \mathrm{~nm}$ and $90 \mathrm{~nm}$. As mentioned in the introduction, it is difficult to obtain a good estimate of the precipitate size distribution using TEM because of the difficulty in getting good statistics, and because of other biases, such as the possibility of overlooking smaller size precipitates which do not happen to be in contrast, so that the lower end of precipitate size distribution is cut off. Thus it is possible that artificially large average precipitate sizes would be reported in TEM studies, because the small precipitates may evade detection. The present method also has its limitations, specially at the higher precipitate sizes when the peak broadening starts to become comparable to the instrument broadening, so that precipitate size increases in the 100-200 $\mathrm{nm}$ may be difficult to detect. The present method gives however a window into the earlier times of precipitation from solution $\left(10^{-20} \mathrm{~h}\right.$ to $\left.10^{-19} \mathrm{~h}\right)$ where precipitate sizes are small.

\subsection{Quantification of absolute precipitate volume fraction}

The basic principle behind the Rietveld method is to refine the least squares fitting of the diffraction profile by systematically varying the various parameters that affect $x$-ray diffraction intensities. The computer adjusts physical parameters in the system and attempts to minimize the difference between the refined theoretical pattern and the data obtained. Currently, there are several computer programs used to perform Rietveld analysis. The program used in this research, GSAS, is maintained at Los Alamos National Laboratory and consists of a set of programs for the processing and analysis of both single crystal and powder diffraction data obtained with $\mathrm{x}$-rays or neutrons. We attended a workshop to learn the GSAS method in Georgia (5/00) and have been using the program to fit our data. The difficulty of the fit comes from the fact that there is a majority phase $(99.5 \%)$ which is heavily textured and which needs to be fit very precisely to obtain a good estimate of the volume fraction of the minority phase of interest.

We are currently working on improving the absolute fit of the diffraction patterns obtained, so that a direct quantification of the precipitate volume fraction can be derived from the data 18 .

3. Microbeam Fluorescence Study of Alloying Elements in the matrix of $\mathrm{Zr}$ alloys (students: O.Delaire, A.Yilmazbayhan, and K.T.Erwin; Collaborators: J.Maser, B.Lai (SRI-CAT, ANL) and R.C.Birtcher, (MSD-ANL))

The alloying element content present in the $\alpha-\mathrm{Zr}$ matrix of $\mathrm{Zr}$ alloys, especially the concentration of transition elements $\mathrm{Fe}, \mathrm{Cr}, \mathrm{Ni}$ is crucial to determining the alloy corrosion behavior. However, the levels of these elements are so low that they cannot be measured by traditional measurement techniques such as EDX on the TEM. There are 
chemical and spectroscopic techniques that can measure very low levels of alloying elements, in the bulk, but these are not suited to determining the alloying element content in specific regions in the microstructure. The unique combination of spatial and elemental resolution needed to measure to study the alloying elements in the hcp matrix of $\mathrm{Zr}$ alloys can be achieved at the microbeam line at APS. The objective of this research program is to use the microbeam line at APS to measure the concentrations of alloying elements in the $\mathrm{Zr}$ alloy matrix using $\mathrm{x}$-ray fluorescence. The intent is to study these quantities as a function of alloy type, irradiation conditions. The information thus obtained will allow more precise and mechanistic predictions of alloy behavior, especially in conditions of high fuel burnup.

Using the $\mathrm{x}$-ray micro-focusing beam line at the APS devised by Yun et al. ${ }^{19}$, we have been studying the concentrations of alloying elements such as Fe in the matrix of zirconium alloys. The apparatus creates a micro-beam with a diameter as small as $0.1 \mu \mathrm{m}$ in diameter. This is a unique capability of this beam line, which allows us to obtain detailed structural information with very high spatial resolution.

We performed microfluorescence examinations of the alloys by using a micro-focused beam on the 2ID-D/E beamlines at APS and placing it on the regions of interest. The beam intensity profile was measured by recording the fluorescence from a $\mathrm{Cr}$ knife edge scanned through the beam. The beam was determined to be $0.24 \mu \mathrm{m}$ wide (FWHM), corresponding to a $0.30 \mu \mathrm{m}$ by $0.24 \mu \mathrm{m}$ footprint on the sample. The geometry of acquisition is shown in Figure 1 (c). We minimized the parasitic fluorescence peak Ar in surrounding air by placing a He-filled bag around the sample. We used the sample stage rastering capabilities to acquire concentration maps for the elements of interest. In order to maximize the precipitate-free regions throughout the depth sampled in the specimen (and also because of beam spreading associated with thick samples), we elected to use thin foils as prepared for conventional TEM examination. We followed a positioning procedure based on line-scans running through the sample, that allowed us to find the thinnest region. Staying in this very thin region, we then moved a small distance $(\sim 5 \mu \mathrm{m})$ off the hole and took a 2D scan (typically $10 \times 10 \mu \mathrm{m}$ ) to identify the location of any second phase particles, and of a suitable matrix spot from where to acquire a detailed fluorescence spectrum. Typical acquisition times for such spectra were on the order of $600 \mathrm{~s}$ to $1500 \mathrm{~s}$, which corresponds to a vastly larger number of incident photons sampling the specimen than during a typical x-ray fluorescence experiment using a conventional $x$-ray tube source (even if run for many hours).

\section{I X-ray Fluorescence Study of alloying element content in zirconium alloys.}

We used the micro beam-focused technique described in section 2 to study the alloying element content in the zirconium matrix. Figure 5 shows the $\mathrm{Fe}, \mathrm{Cr}, \mathrm{Zr}$, and $\mathrm{Sn}$ fluorescence scans of a thin foil region of Zircaloy-4, taken on a $10 \mu \mathrm{m} \times 10 \mu \mathrm{m}$ grid and a step size of $0.4 \mu \mathrm{m}$. The $2 \mathrm{D}$ scan shows the position of intermetallic precipitates. We then placed the beam on the region in between the precipitates and performed a more detailed scan of the smaller region (typically 2 by $2 \mu \mathrm{m}$, with a $0.1 \mu \mathrm{m}$ step size and an acquisition time of 5 seconds per point) to ensure that no large variations of $\mathrm{Fe}$ content

A. T. Motta $\quad$ Final Report DE-FG07-98_ID13637 
exist within those regions. We then positioned the beam in this lowest Fe region, and acquired point spectra with long acquisition times, typically for 600 to 1,500 seconds. These spectra serve as the basis for our quantitative analysis of the matrix composition in those samples.

Figure 6 (a) shows several fluorescence spectra acquired from four standards: (i) a TEM foil of a quenched Zircaloy-4 sample, (ii) a bulk sample of nominally pure zirconium, (ii) bulk ultra pure zirconium (acquired from Chalk River Laboratories), and (iv) from TEM foil of quenched ZIRLO. In these samples, the concentrations should be close to those obtained from overall bulk measurements. We find that the Fe peaks are highest for Zircaloy-4, next for ZIRLO, then nominally pure $\mathrm{Zr}$ and lastly ultra pure $\mathrm{Zr}$. The spectra are normalized by the $\mathrm{Sn}$ counts, since the $\mathrm{Sn}$ concentration is homogeneous in the $\mathrm{Zr}$ matrix in order to account for the different number of counts from sample to sample, resulting from different sample thicknesses. The value for the Fe content in the Zircaloy 4 matrix is higher than that found in nominally pure $\mathrm{Zr}$, but considerably lower than that found in the quenched sample. Figure 6 (b) shows the same Zircaloy-4 quenched spectrum superimposed on the spectrum measured on a matrix spot of TEM foil made of fully recrystallized Zircaloy-4. The linear analysis gives an Fe concentration in the matrix of about $300 \mathrm{ppm}$ and $307 \mathrm{ppm}$ for $\mathrm{Cr}$.

Table 3 shows a linear analysis of the composition of the alloys. The linear analysis is performed by taking the integrated ratio of the counts for a particular elemental peak and finding their ratio to a known standard (quenched Zircaloy-4 or quenched ZIRLO). The procedure is the following: by integration we find the total number of counts in the $\mathrm{Zr}$ peak and normalize that value to $10^{6}$ counts. The same multiplication factor is then applied to the elemental peak; we can then compare the results obtained from other alloys. The linear analysis shows that if we assume that the alloying element concentrations to be the measured bulk values in the quenched alloys(e.g., assuming the $\mathrm{Fe}$ and $\mathrm{Cr}$ concentration in Zircaloy-4 to be $2400 \mathrm{ppm}$ and $1130 \mathrm{ppm}$ (Table 1)), we can reproduce the concentrations in the other alloys (compare non-bolded values in Table 3 with those in Table 1.) That is, the ratio of the alloying element concentrations is reproduced by the measurements. This gives confidence that the results are reliable. Table 3 also shows the results from the Monte Carlo program MSIM5D, discussed in the next section.

\subsection{Monte Carlo Simulation of Fluorescence Spectra}

To analyze the fluorescence spectra we used the MSIM5D program 6 . This Monte Carlo program simulates the interaction of an $\mathrm{x}$-ray photon beam with a slab sample of arbitrary composition, explicitly taking into account all the scattering and fluorescence emission processes from both the material and from air. In performing the analysis, we entered our experimental conditions (sample composition, incident energy, geometry, acceptance angle, etc.) as input for the simulation (we used the detector efficiency provided by the manufacturer to simulate the response of our EDS detector). We then compared the simulated spectrum with our experimental data and adjusted the input concentrations until the spectra matched. The concentrations that make the simulations agree with the 
measured spectra are our calculated concentrations. In this fitting procedure, spectra had to be normalized to account for unknown sample thickness: this was done by equating the simulated and experimental intensities obtained from an element of known concentration. Because the detector efficiency falls fairly sharply with energy in the region below 3 $\mathrm{keV}$, we used the $\mathrm{Sn} \mathrm{L}$ peaks to normalize the spectrum rather than using the $\mathrm{Zr} \mathrm{L}$ peaks, i.e., for any given spectrum we normalized the data so that the curves agreed with experimental values in the $\mathrm{Sn} \mathrm{L}$ region. The rest of the curve was fit by varying the concentration of the alloying elements with no other adjustable parameters. By performing this simulation on the standards (quenched alloys with a homogeneous distribution of alloying elements, and equal to the bulk concentration), we can verify that the simulation and fitting procedure reproduce the known compositions. Figure 9 (a) shows the measured and simulated spectra for quenched Zircaloy-4 and matrix of Zircaloy- 4 and Figure 9 (b) shows the equivalent values for ZIRLO. The values of the alloying element concentrations used to fit the spectra are shown in the legend. We note that the curve fit is very good, for all the elements in the alloy. Even the $\mathrm{Zr}$ peak agrees well, despite the rapid variation of detector efficiency in its region. The agreement with the measured bulk concentrations shown in table 1 is excellent. We also used the program to analyze the results obtained for ultra pure $\mathrm{Zr}$, finding that the Fe concentration in that case is $30 \mathrm{ppm}$, showing that the elemental sensitivity of our experimental setup is high.

We analyzed the fluorescence spectra obtained at a Zircaloy-4 matrix point such as shown in Figure 5. The concentrations needed to fit the spectrum are Sn: 1640 ppm, Fe: $300 \mathrm{wt}$ ppm, Cr: $270 \mathrm{wt}$ ppm. Measuring the level of Fe and other alloying elements in the matrix is one of the primary goals of this experiment, so we made concerted efforts to ensure that the measured alloying element concentrations are representative of the matrix. Thus we used TEM samples, to minimize the problem of hitting a "buried" precipitate, carefully locating the beam in a region away from the precipitate peaks, and performing several measurements at different spots in the matrix region. The matrix concentrations of $\mathrm{Fe}$ and $\mathrm{Cr}$ above are on the order of measurements performed in Zircaloy-2 by Kruger et al. 20 who found a matrix value of $\sim 140 \mathrm{wt}$. ppm using atom probe. The results agree well with the atom probe measurements of Wadman et al. 21 who found $\mathrm{Fe}$ concentrations in the Zircaloy-4 matrix between 230 and $380 \mathrm{wt}$. ppm. If the current results are valid, this could mean that the actual concentration of alloying elements in the matrix is higher than the equilibrium concentration. These alloying elements may be in metastable equilibrium in the matrix, possibly associated with other alloying elements (such as $\mathrm{O}$ or $\mathrm{Sn}$ ), and with lattice defects, such as dislocations and stacking faults.

\section{Neutron Irradiated Zircaloy-4 Samples}

We were in contact with Bettis Laboratory to obtain neutron-irradiated Zircaloy TEM samples to perform studies similar to those in parts 2 and 3 above. However, logistical difficulties in shipping the samples impeded our examination of the samples in the time frame of the proposal. The set of samples to be examined include non-irradiated, low medium and high fluence samples. We will examine these as soon as they can be shipped to Argonne, and prepared for examination. 


\section{TABLES}

Table 1: Chemical analysis of various zirconium alloys performed by Luvak Inc.

All values are expressed in weight percent.

\begin{tabular}{|l|l|l|l|l|}
\hline \multicolumn{1}{|c|}{ Element } & \multicolumn{1}{|c|}{ Zircaloy-2 } & \multicolumn{1}{c|}{ Zircaloy-4 } & \multicolumn{1}{c|}{ ZIRLO } & Detection Limit \\
\hline Aluminum & 0.0061 & 0.0058 & 0.012 & 0.0005 \\
\hline Carbon & 0.002 & 0.003 & 0.002 & 0.0010 \\
\hline Chromium & 0.11 & 0.11 & 0.001 & 0.0005 \\
\hline Copper & 0.0046 & 0.0020 & 0.0020 & 0.0005 \\
\hline Hafnium & $<0.004$ & $<0.004$ & $<0.004$ & 0.0040 \\
\hline Iron & 0.14 & 0.24 & 0.10 & 0.0005 \\
\hline Manganese & $<0.001$ & $<0.001$ & $<0.001$ & 0.0010 \\
\hline Molybdenum & $<0.001$ & $<0.001$ & $<0.001$ & 0.0010 \\
\hline Nickel & 0.063 & 0.0034 & $<0.001$ & 0.0010 \\
\hline Niobium & --- & -- & 1.23 & 0.0010 \\
\hline Nitrogen & 0.003 & 0.002 & 0.005 & 0.0010 \\
\hline Oxygen & 0.112 & 0.112 & 0.145 & 0.0010 \\
\hline Silicon & 0.0097 & 0.0095 & 0.013 & 0.0010 \\
\hline Tin & 1.55 & 1.64 & 1.08 & 0.0010 \\
\hline Titanium & 0.0020 & 0.0012 & 0.0019 & 0.0010 \\
\hline Tungsten & $<0.004$ & $<0.004$ & $<0.004$ & 0.0040 \\
\hline Zirconium & Balance & Balance & Balance & \\
\hline & & & & \\
\hline
\end{tabular}


Table 2: Annealing Schedules and Cumulative Annealing Parameter for alloys examined

\begin{tabular}{|c|c|c|c|}
\hline $\begin{array}{c}\text { Sample } \\
\text { Designation }\end{array}$ & $\begin{array}{c}\text { Annealing } \\
\text { Temperature }\left({ }^{\circ} \mathrm{C}\right) \\
\end{array}$ & $\begin{array}{l}\text { Annealing } \\
\text { Time (h) } \\
\end{array}$ & CAP (h) \\
\hline $\begin{array}{l}\mathrm{Mz} 4 \mathrm{q} \\
\mathrm{Mz} 2 \mathrm{q}\end{array}$ & $\mathrm{Cl}_{\mathrm{S}}$ & 0 & 0 - As quenched condition \\
\hline $\begin{array}{l}\mathrm{Mz} 4 \mathrm{e} 20 \mathrm{c} \\
\mathrm{Mz} 2 \mathrm{e} 20 \mathrm{c}\end{array}$ & 605 & 1 & $1.63 \times 10^{-20}$ \\
\hline $\begin{array}{l}\text { Mz4e19c } \\
\text { Mz2e19c }\end{array}$ & 650 & 1 & $1.5 \times 10^{-19}$ \\
\hline $\begin{array}{l}\mathrm{Mz4e} 18 \mathrm{c} \\
\mathrm{Mz} 2 \mathrm{e} 18 \mathrm{c}\end{array}$ & 700 & 1 & $1.4 \times 10^{-18}$ \\
\hline $\begin{array}{l}\text { Mz4e17c } \\
\text { Mz2e17c }\end{array}$ & 759 & 1 & $1.46 \times 10^{-17}$ \\
\hline $\begin{array}{l}\text { Mz4e16c } \\
\text { Mz2e16c }\end{array}$ & 815 & 1 & $1.07 \times 10^{-16}$ \\
\hline $\begin{array}{l}\mathrm{Mz} 4 \mathrm{q} \\
\mathrm{Mz} 2 \mathrm{q}\end{array}$ & 0 & 0 & 0 - As quenched condition \\
\hline $\begin{array}{l}\text { Mz4e19t } \\
\text { Mz2e19tc }\end{array}$ & 720 & 0.0312 & $1.1 \times 10^{-19}$ \\
\hline $\begin{array}{l}\text { Mz4e18t } \\
\text { Mz2e18t }\end{array}$ & 730 & 0.312 & $1.49 \times 10^{-18}$ \\
\hline $\begin{array}{l}\mathrm{Mz} 4 \mathrm{e} 17 \mathrm{t} \\
\mathrm{Mz} 2 \mathrm{e} 17 \mathrm{t}\end{array}$ & 725 & 3.12 & $1.22 \times 10^{-17}$ \\
\hline $\begin{array}{l}\text { Mz4e16t } \\
\text { Mz2e16t }\end{array}$ & 725 & 31.2 & $1.22 \times 10^{-16}$ \\
\hline $\begin{array}{l}\text { Mz463e18 } \\
\text { Mz263e18 }\end{array}$ & 755 & 0.5 & $6.31 \times 10^{-18}$ \\
\hline $\begin{array}{l}\text { Mz465e19t } \\
\text { Mz265e19t }\end{array}$ & 725 & 0.1667 & $6.53 \times 10^{-19}$ \\
\hline
\end{tabular}

A. T. Motta 
Table 3: Calculated Alloying Element Concentrations

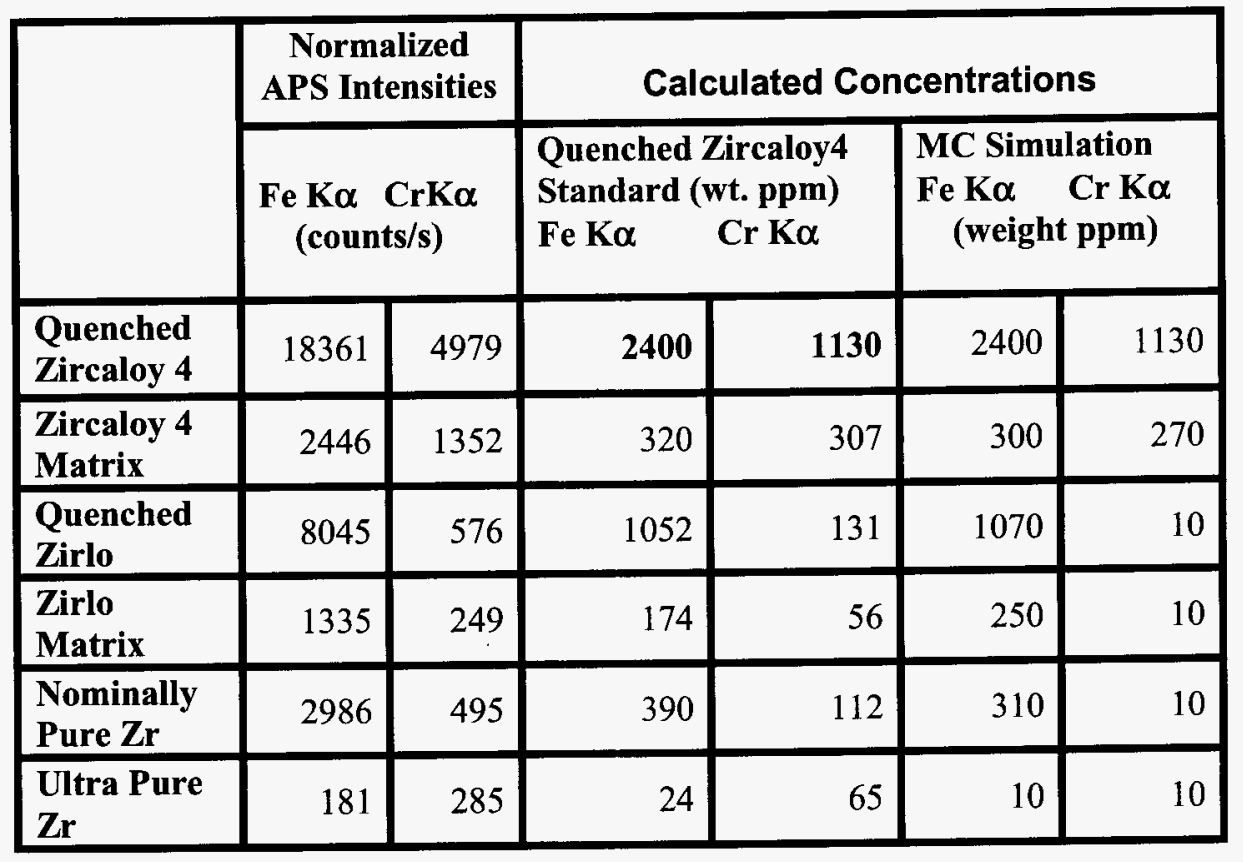

A. T. Motta 
Table 4: Lattice Parameters of Second Phase Precipitates (nm)

\begin{tabular}{|l|ll|ll|ll|}
\hline & $\mathrm{Zr}(\mathrm{Cr}, \mathrm{Fe})_{2}$ & $(\mathrm{hcp} \mathrm{C} 14)$ & \multicolumn{2}{|l|}{$\mathrm{Zr}_{2}(\mathrm{Ni}, \mathrm{Fe})(\mathrm{bct} \mathrm{C16})$} & $\mathrm{Zr}-\mathrm{Nb}-\mathrm{Fe}(\mathrm{hcp}$ C14 $)$ \\
\hline Zircaloy-2 & $\mathrm{a}=0.500$ & $\mathrm{c}=0.820$ & $\mathrm{a}=0.648$ & $\mathrm{c}=0.526$ & $\mathrm{x}$ & \\
\hline Zircaloy-4 & $\mathrm{a}=0.501$ & $\mathrm{c}=0.821$ & $\mathrm{x}$ & & $\mathrm{x}$ & \\
\hline ZIRLO & $\mathrm{x}$ & & $\mathrm{x}$ & $\mathrm{a}=0.53 \quad \mathrm{c}=0.875$ \\
\hline
\end{tabular}




\section{Figure Captions}

Figure 1: A) schematic view of the experimental setup at the 2-BM beamline at the Advanced Photon Source; B) diffraction geometry used for the experiment; (C) acquisition geometry for the fluorescence experiments.

Figure 2: Bright Field Transmission Electron Micrographs of (a) quenched Zircaloy-4, (b) fully annealed $\left(10^{-16} \mathrm{~h}\right)$ Zircaloy-4 and (c) ZIRLO.

Figure 3: Synchrotron radiation diffraction patterns for Zircaloy-2 and Zircaloy-4 (both annealed to $10^{-16} \mathrm{~h}$ ), and ZIRLO (annealed to $10^{-18} \mathrm{~h}$ ). The phases preent are shown in the indexing bars in the figures.

Figure 4: Synchrotron radiation diffraction patterns for Zircaloy-4 and Zircaloy-2 as a function of annealing parameter.

Figure 5: 2-D fluorescence scans of $\mathrm{Zr}, \mathrm{Sn}, \mathrm{Fe}$ and $\mathrm{Cr}$, obtained from the examination of a TEM thin foil of Zircaloy-4.

Figure 6: Fluorescence spectra obtained from (a) quenched Zircaloy-4 TEM foil, quenched ZIRLO TEM foil and ultra pure Zr (bulk sample) and (b) quenched Zircaloy 4 TEM foil and the matrix region in a TEM foil of annealed Zircaloy-4.

Figure 7: Normalized precipitate volume fraction versus annealing parameter (CAP) for $\mathrm{Zr}(\mathrm{Cr}, \mathrm{Fe})_{2}$ precipitates in Zircaloy-4.

Figure 8: Average particle size versus annealing parameter as measured by diffraction line broadening.

Figure 9: (a) X-Ray intensity versus energy for quenched Zircaloy-4 and the matrix region of a fully recrystallized Zircaloy-4 TEM sample (solid lines) and MSIM5D Monte Carlo simulations (dashed lines), using the concentrations shown in the figure.

(b) X-Ray intensity versus energy for quenched ZIRLO and the matrix region of a fully recrystallized ZIRLO TEM sample (solid lines) and MSIM5D Monte Carlo simulations (dashed lines), using the concentrations shown in the figure 


\section{FIGURES}

Figure 1
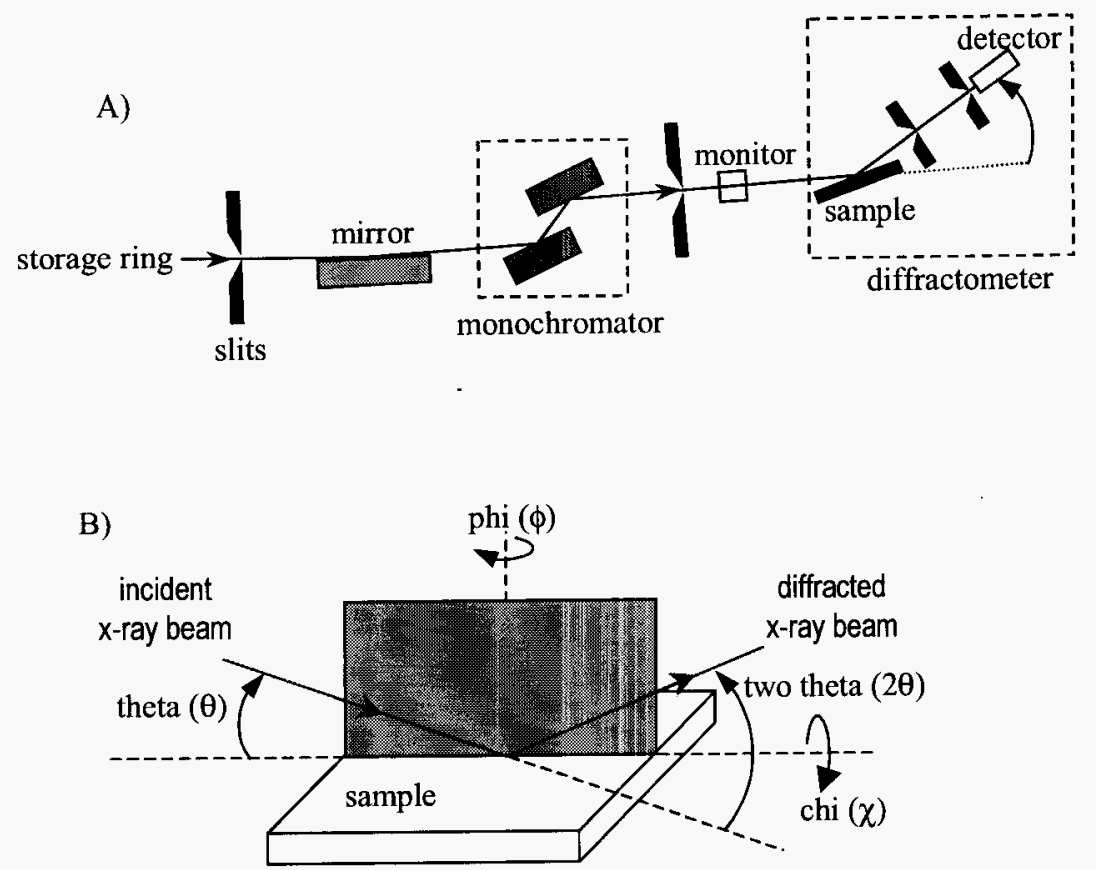

C)

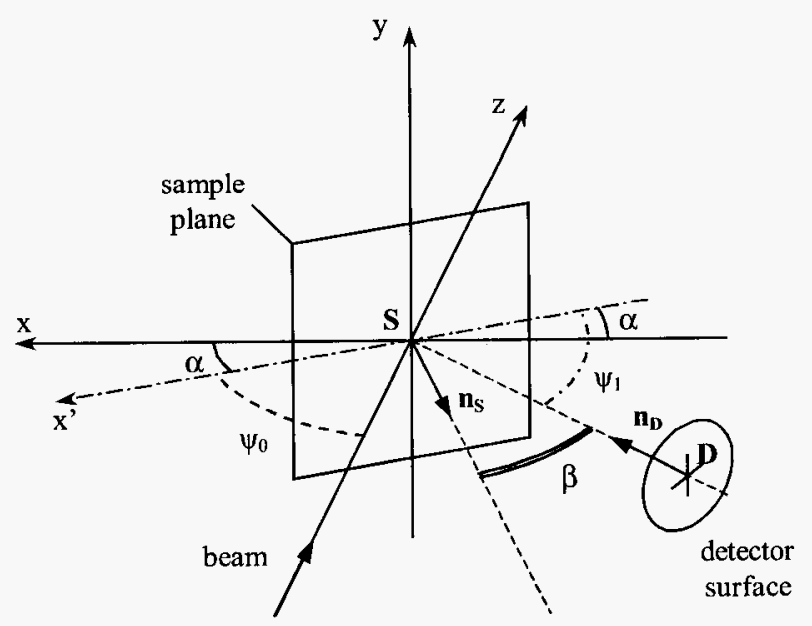

A. T. Motta

Final Report DE-FG07-98_ID13637 
Figure 2

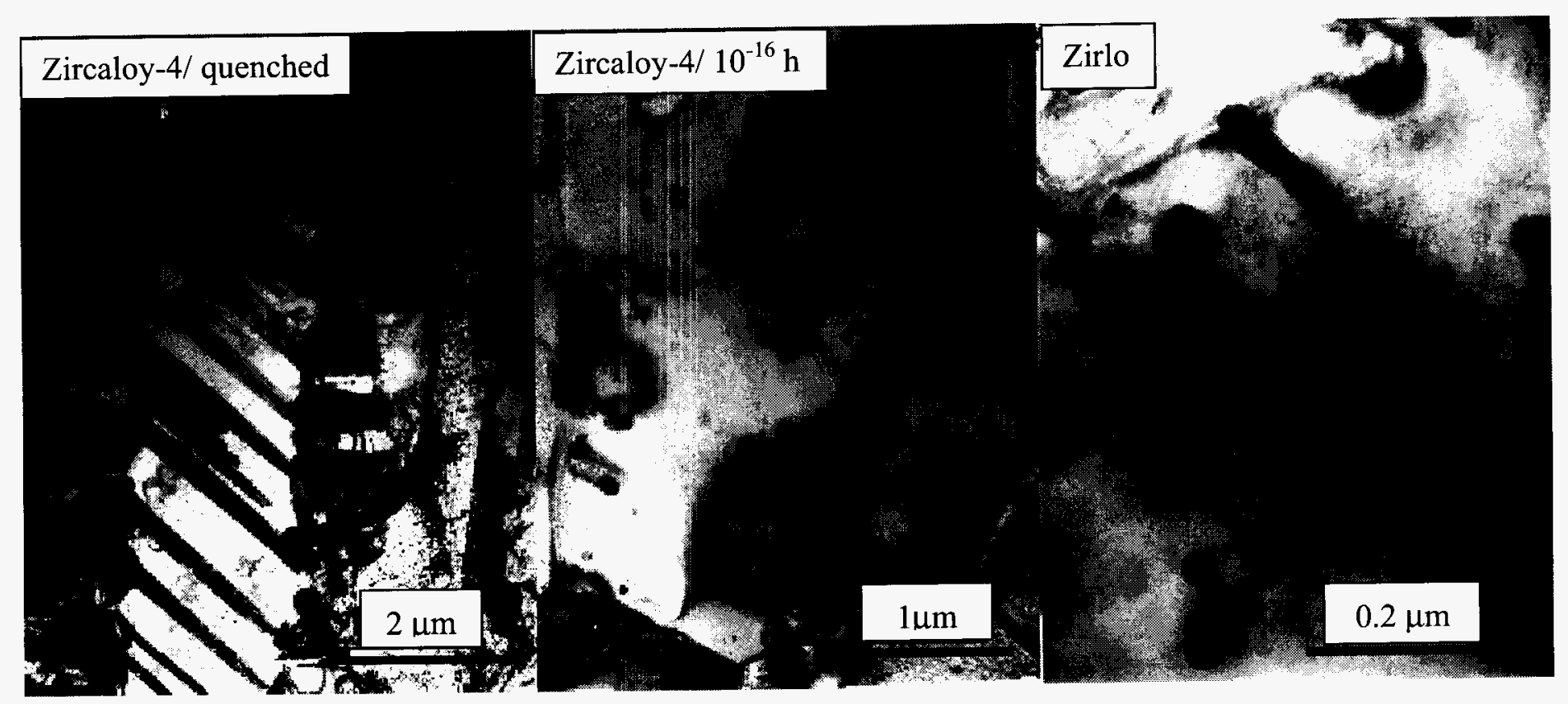

A. T. Motta

Final Report DE-FG07-98_ID13637 


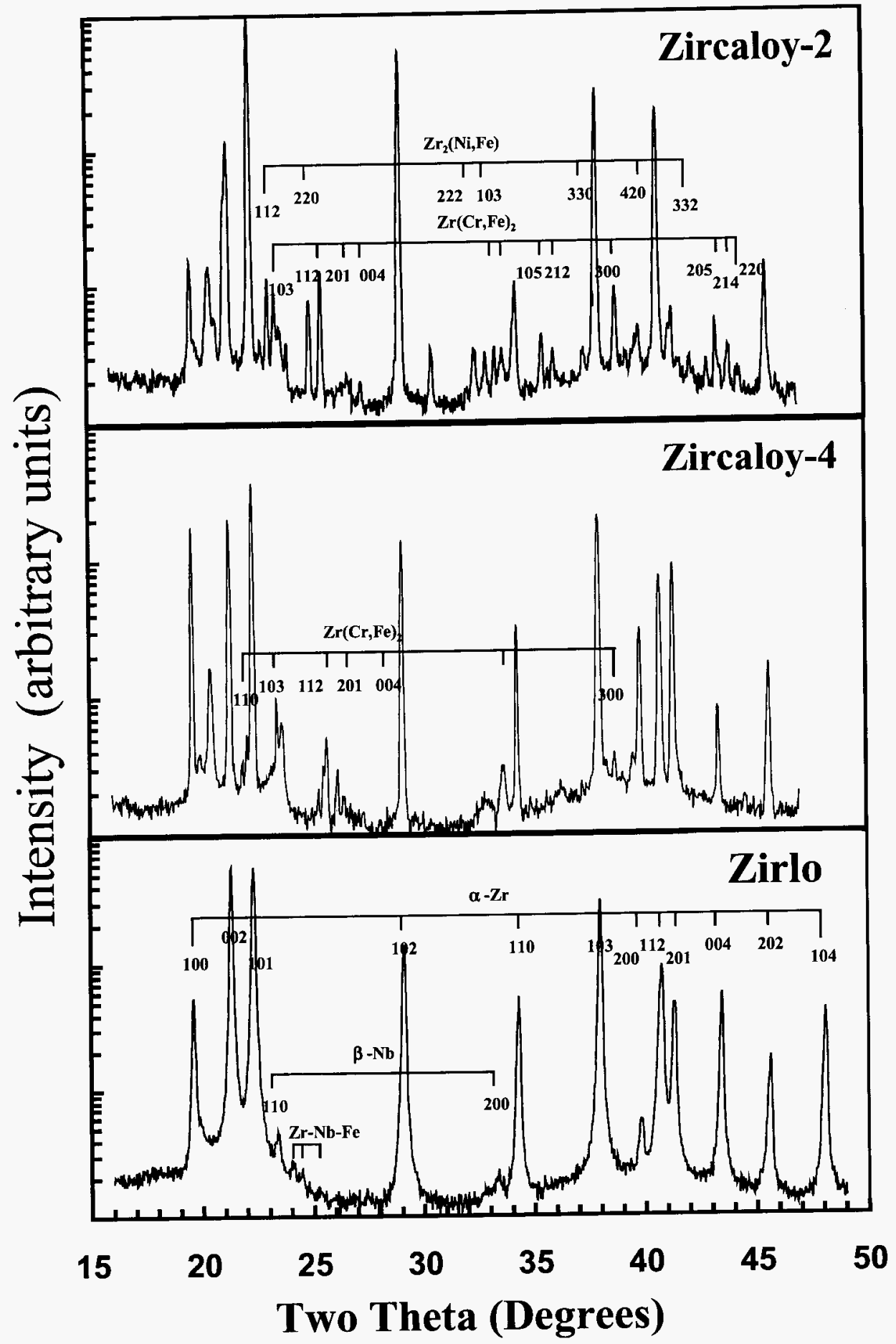

Figure 3

A. T. Motta

Final Report DE-FG07-98_ID13637 

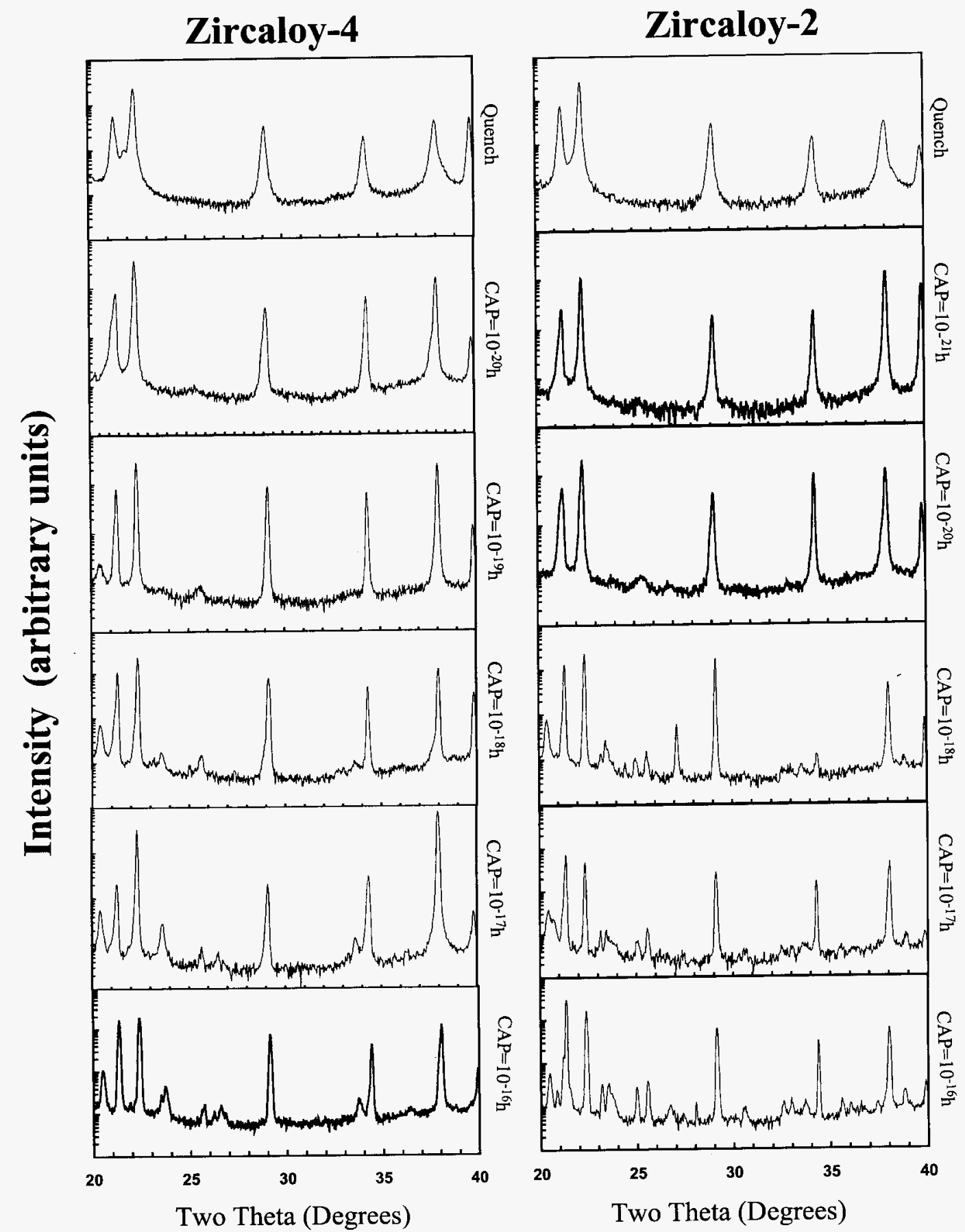

Figure 4

A. T. Motta

Final Report DE-FG07-98_ID13637 


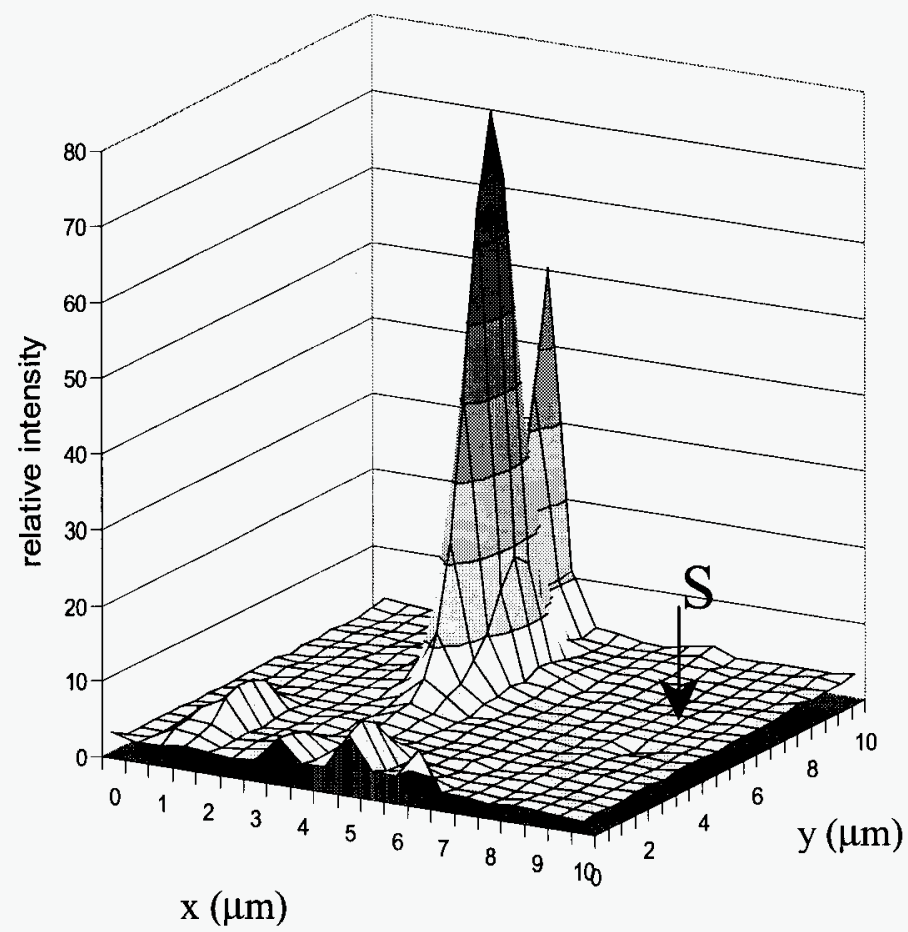

Figure 5 

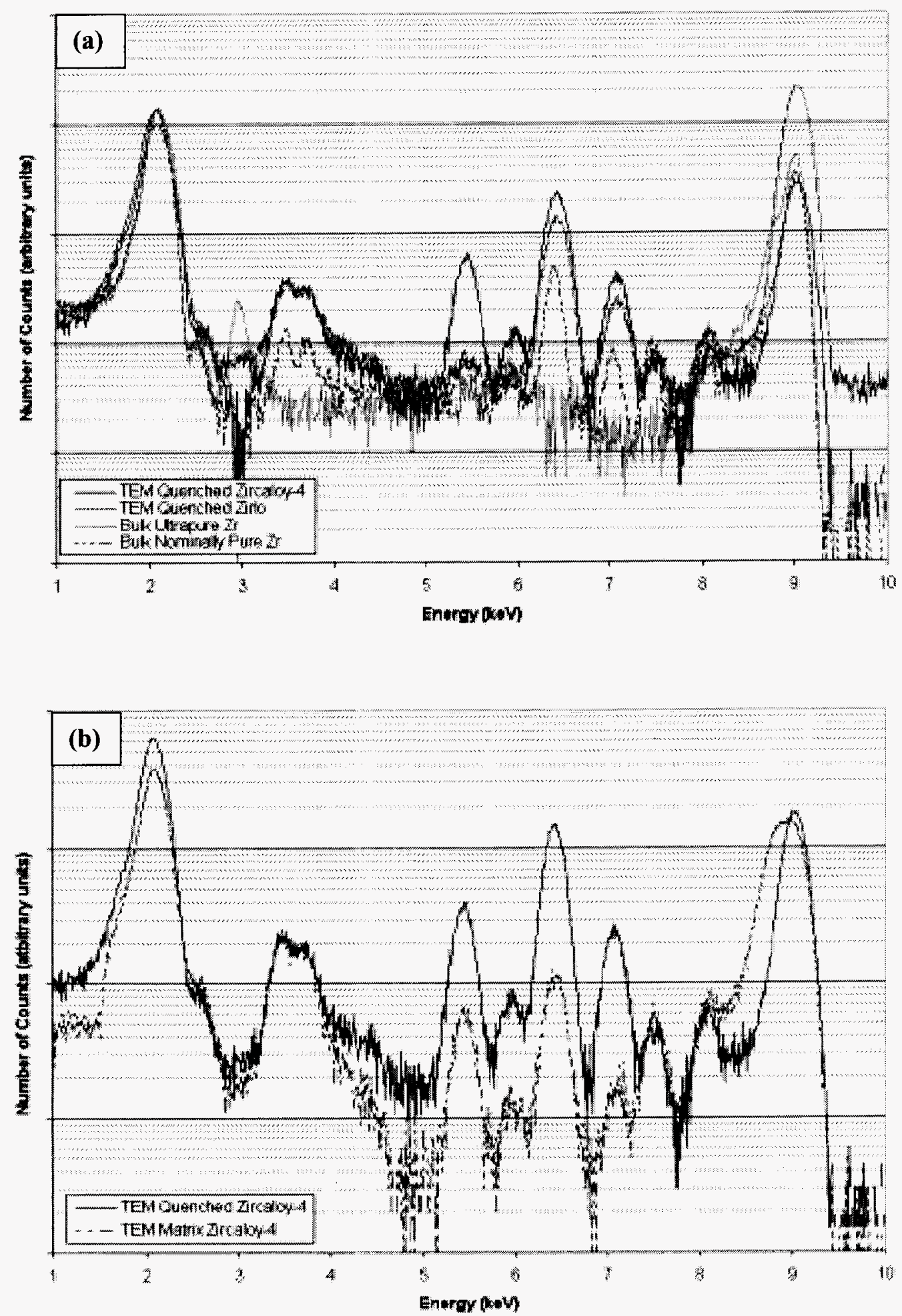

A. T. Motta

Final Report DE-FG07-98_ID13637 


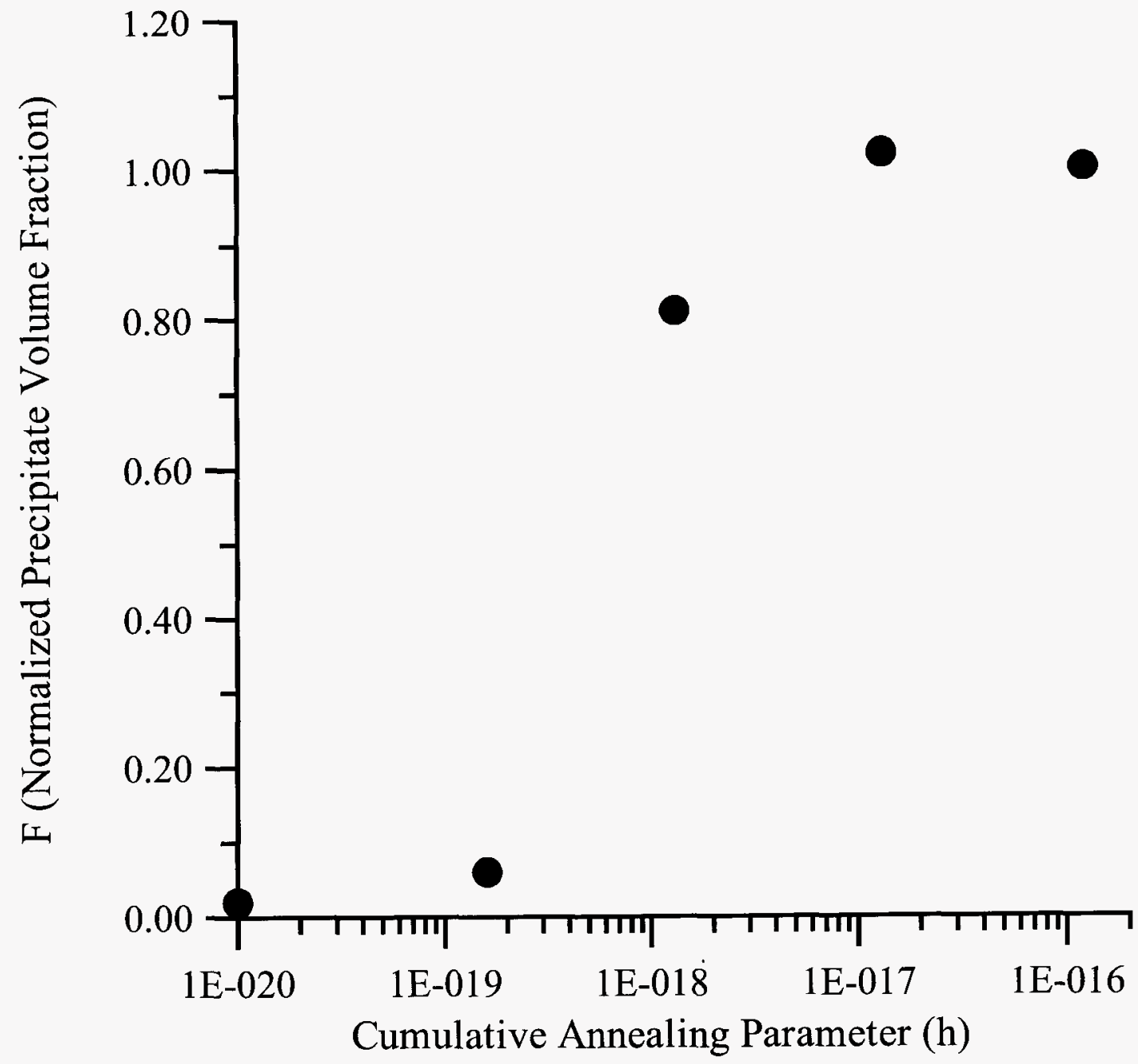

Figure 7 


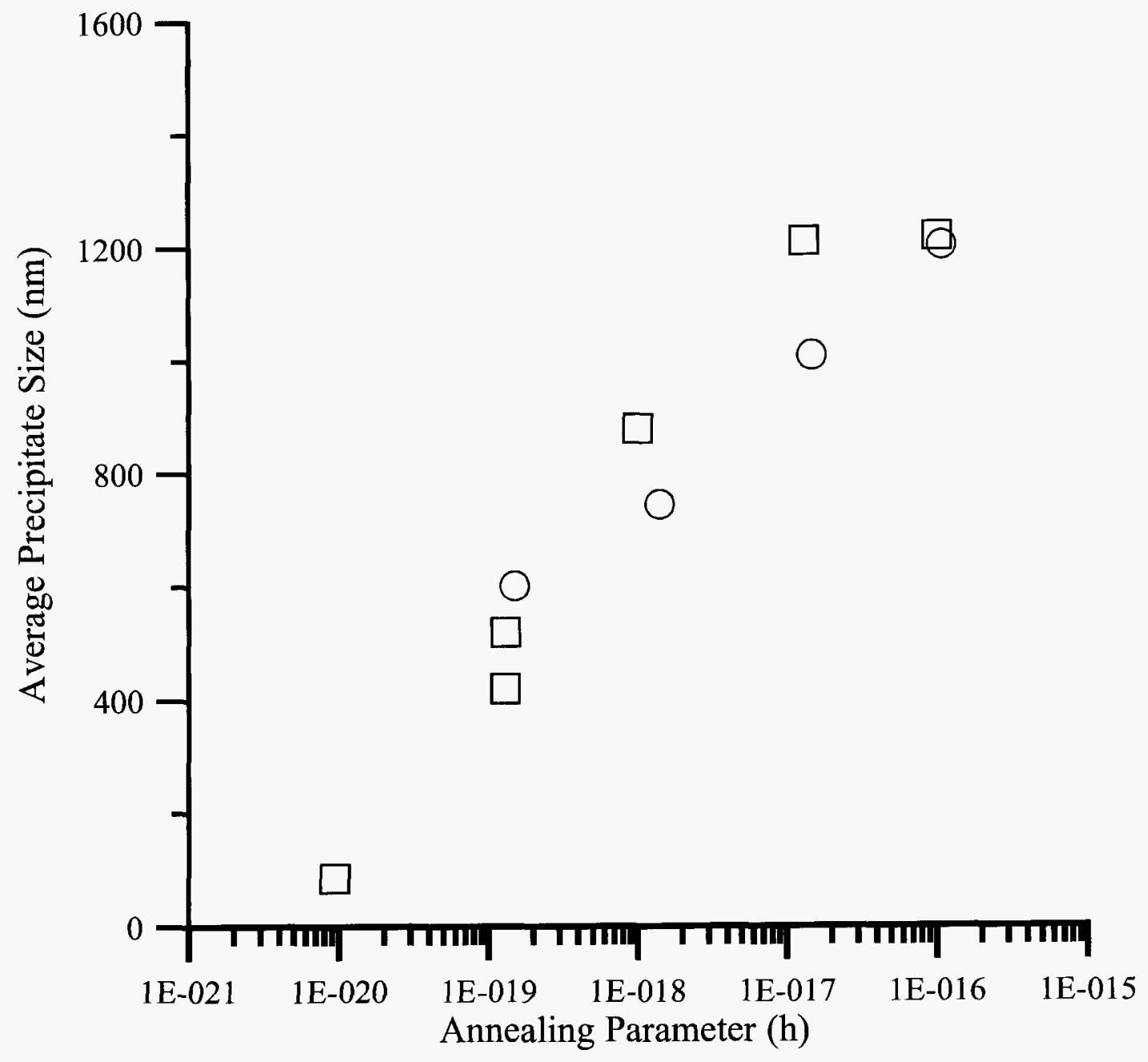

Figure 8 
figure 9
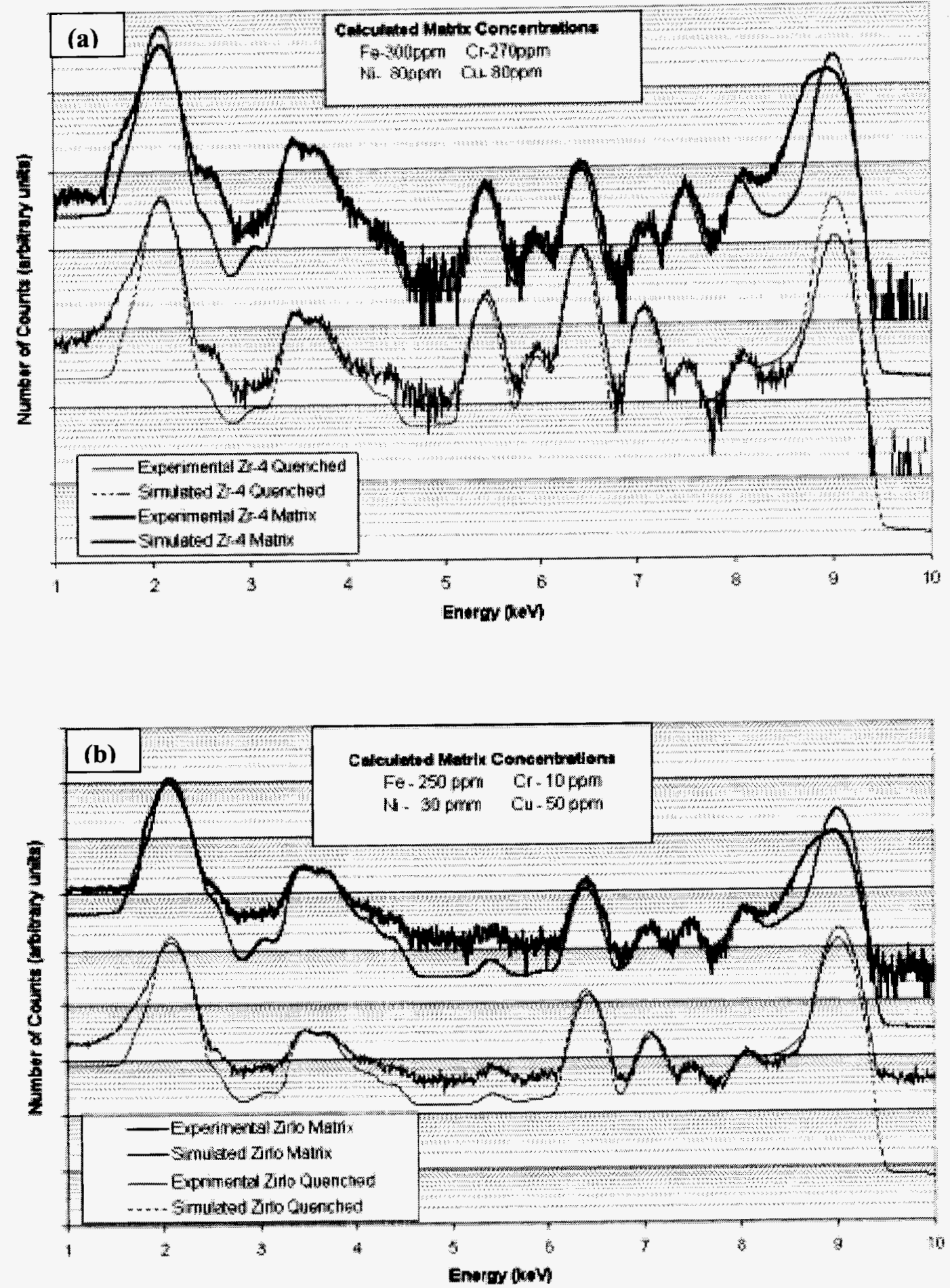

A. T. Motta

Final Report DE-FG07-98_ID13637

The Pennsylvania State University 


\section{Appendix}

\section{Publications}

Erwin, O. Delaire, A.T. Motta et al., "Observation of second-phase particles in bulk zirconium alloys using synchrotron radiation," Journal of Nuclear Materials 294, (2001) 299-304.

O. Delaire, A. Yilmazbayhan, A.T. Motta et al., "Measurement of Zircaloy-4 Matrix Alloying Element Content using synchrotron micro beam $\mathrm{x}$-ray fluorescence," Journal of Nuclear Materials in preparation for submittal (2001).

A. T. Motta, K.T. Erwin, O. Delaire et al., "Synchrotron Radiation Study of Second Phase Particles and Alloying elements in Zircaloy-4," 13th International Symposium on Zirconium in the Nuclear Industry, ASTM Special Technical Publication 1423, P. Rudling, G. Moan, C.Lemaignan, eds. ASTM, France, 2001, in press.

J. Wang, A.T. Motta, and R.J. Comstock, "Crystal Structure of Intermetallic Precipitates in ZIRLO," to be submitted to the Journal of Nuclear Materials (2001).

O. Delaire, K.T. Erwin, A.T. Motta et al., "Study of Alloying Elements in the Matrix of $\mathrm{Zr}$ alloys using the Advanced Photon Source at Argonne National Laboratory," presented at the Proceedings of ICONE-8, 8th International Conference on Nuclear Engineering, Baltimore, 2000 paper $\# 8320$.

K.T. Erwin, O. Delaire, A.T. Motta et al., "Study of Second Phase Particles in Zr alloys using the Advanced Photon Source at Argonne National Laboratory," presented at the Proceedings of ICONE-8, 8th International Conference on Nuclear Engineering, Baltimore, 2000, paper \#8319.

\section{Graduate Student Theses}

Kenneth T. Erwin, "Study of Second Phase Particles in Zirconium Alloys using Synchrotron Radiation," M.Sc. Thesis , Penn State University, 2000.

Olivier Delaire, "Study of the alloying element content in zirconium alloys using synchrotron radiation microscopic x-ray fluorescence," M.Sc Thesis., Penn State University, 2000.

Sarah Jurgensmeier, "Rietveld Analysis of Synchrotron X-ray Diffraction of Second Phase Particles in Zr Alloys," M.Sc. Thesis, Penn State University, expected 2002.

A. T. Motta

Final Report DE-FG07-98_ID13637

The Pennsylvania State University 


\section{References}

${ }^{1}$ K.T. Erwin, O. Delaire, A.T. Motta et al., "Observation of second-phase particles in bulk zirconium alloys using synchrotron radiation," Journal of Nuclear Materials 294 (3) 299 ,

${ }^{2}$ K.T. Erwin, O. Delaire, A.T. Motta et al., "Study of Second Phase Particles in Zr alloys using the Advanced Photon Source at Argonne National Laboratory," presented at the Proceedings of ICONE-8, 8th International Conference on Nuclear Engineering, Baltimore, 2000 paper \#8320

${ }^{3}$ K.T. Erwin, "Study of Second Phase Particles in Zirconium Alloys using Synchrotron Radiation," M.Sc. Thesis in Nuclear Engineering, Penn State University, 2000.

${ }^{4}$ A. T. Motta, K.T. Erwin, O. Delaire et al., "Synchrotron Radiation Study of Second Phase Particles and Alloying elements in Zircaloy-4," ASTM STP 1423, 13th International Symposium on Zirconium in the Nuclear Industry, Annecy, France, 2001, in press.

$5_{L}$. Vincze, K. Janssens, F. Adams et al., "A general Monte Carlo simulation of EDXRF spectrometers - II: Polarized monochromatic radiation, homogeneous samples," Spectrochimica Acta 50B (2), 127-147 (1995).

${ }^{6} \mathrm{~L}$. Vincze, K. Janssens, F. Adams et al., "A general Monte Carlo simulation of energy-dispersive X-ray fluorescence spectrometers - Part 3. Polarized polychromatic radiation, homogeneous samples," Spectrochimica Acta Part B 50, 1481-1500 (1995).

7O. Delaire, K.T. Erwin, A.T. Motta et al., "Study of Alloying Elements in the Matrix of $\mathrm{Zr}$ alloys using the Advanced Photon Source at Argonne National Laboratory," presented at the Proceedings of ICONE-8, 8th International Conference on Nuclear Engineering, Baltimore, 2000 paper $\# 8319$

${ }^{8}$ O. Delaire, A. Yilmazbayhan, A.T. Motta et al., "Measurement of Zircaloy-4 Matrix Alloying Element Content using synchotron micro beam x-ray fluorescence," Journal of Nuclear Materials in preparation for submittal (2001).

${ }^{9} \mathrm{O}$. Delaire, "Study of the alloying element content in zirconium alloys using synchrotron radiation microscopic x-ray fluorescence," M.Sc. Thesis in Nuclear Engineering, Penn State University, 2000.

10 J. P. Gros and J. F. Wadier, "Precipitate Growth Kinetics in Zircaloy-4," Journal of Nuclear Materials 172, 85-96 (1990).

$11_{J}$. Wang, A.T. Motta, and R.J. Comstock, "Crystal Structure of Intermetallic Precipitates in ZIRLO," to be submitted to the Journal of Nuclear Materials (2001). ${ }^{12}$ G.P. Sabol, G.R. Kilp, M.G. Balfour et al., "Development of a Cladding Alloy for High Burnup," ASTM STP1023, Eighth International Symposium on Zirconium in the Nuclear Industry, San Diego, 1989 (unpublished).

${ }^{13} \mathrm{D}$. Charquet and E. Alheritiere, presented at the Workshop on Second-Phase particles in Zircaloy, Erlangen, Germany, 1985. 
${ }^{14}$ E.E. Havinga, H. Damsma, and P. Hokkeling, "Compounds and Pseudo Binary Alloys with CuA12-C16-type structure, Pt.1 Preparation and X-ray results," Journal of the LessCommon Metals 27 (2), 169-186 (1972).

15 A.C. Larson and R.B. VonDreele, Report No. LAUR 86-748, 1994.

16A.C. Larson and R.B. Von Dreele, Report Report No. LAUR 86-748, 2000.

${ }^{17}$ B.D. Cullity, Elements of X-ray Diffraction (Addison-Wesley, Reading, MA, 1978).

18 S. Jurgensmeier, "Rietveld Analysis of Synchrotron X-ray Diffraction of Second Phase Particles in Zr Alloys," M.Sc. Thesis in Materials, Penn State University, 2002.

${ }^{19}$ W. Yun, B. Lai, Z. Cai et al., "Nanometer Focusing of Hard X-Rays by Phase Zone Plates," Rev. Sci. Instrum. 70, 2238 (1999).

${ }^{20}$ R.M. Kruger, R.B.Adamson, and S.S.Brenner, Journal of Nuclear Materials 189, 193 200 (1992).

$21_{\text {B. Wadman and H.-O. Andren, "Microanalysis of the Matrix and the Oxide-Metal }}$ Interface of Uniformly corroded Zircaloy", ASTM STP 1132, Zirconium in the Nuclear Industry: Ninth international Symposium, Kobe, Japan, 1991. 